\title{
Decreased Cerebrospinal Fluid and Serum Concentrations of Pigment Epithelium-Derived Factor in Drug-Refractory Epilepsy Patients
}

\author{
Dan Chen ${ }^{1}$, Zheng Xiao' ${ }^{2}$, Liang Wang ${ }^{2}$, Fei Xiao ${ }^{2}$, Zhi Qin Xi² ${ }^{2}$ Xue Feng Wang ${ }^{2}$ and Qiao Cheng ${ }^{3 *}$ \\ ${ }^{1}$ Department of Neurosurgery, China \\ ${ }^{2}$ Department of Neurology, China \\ 3Department of Endocrine and Breast Surgery, China \\ *Corresponding author: Qiao Cheng, Department of Endocrine and Breast Surgery, China
}

\begin{abstract}
ARTICLE INFO
Received: 幽 May 15, 2019

Published: 豐 June 06, 2019

Citation: Dan Chen, Zheng Xiao, Liang Wang, Fei Xiao, Zhi Qin Xi, Xue Feng Wang, Qiao Cheng. Decreased Cerebrospinal Fluid and Serum Concentrations of Pigment Epithelium-Derived Factor in Drug-Refractory Epilepsy Patients. Biomed J Sci \& Tech Res 18(4)-2019. BJSTR. MS.ID.003184.
\end{abstract}

Abbreviations: PEDF: Pigment Epithelium Derived Factor; CSF: Cerebrospinal Fluid; ELISA: Sandwich Enzyme Linked Immunosorbent Assays; CNS: Central Nervous System
ABSTRACT

Objectives: Considering the known potency of PEDF as a neuron protectant, we designed this study to quantitatively examine the alternation of PEDF level in the CSF of drug-effective epilepsy patients compared with drug-refractory epilepsy patients and with healthy controls. Meanwhile, the serum concentrations of PEDF were detected.

Design and Methods: A total of 52 patients (including 29 drug-effective and 23 drug-refractory epilepsy patients) and 20 healthy controls participated in the study. The cerebrospinal fluid (CSF) and serum concentrations of PEDF were detected in drug-effective and drug-refractory epilepsy and control groups by sandwich enzyme-linked immunosorbent assays (ELISA).

Results: CSF and serum PEDF were increased in drug-effective epilepsy but were dramatically decreased in drug-refractory epilepsy compared with controls.

Conclusion: For the first time, we suggest that the neurotrophic/neuroprotective activities of PEDF might contribute to the more favorable outcome in drug-effective epilepsy patients.

Keywords: Pigment Epithelium Derived Factor; Epilepsy; Cerebrospinal Fluid; Serum; Enzyme Linked Immunosorbent Assays; Apoptosis; Glutamic Acid

\section{Introduction}

Epilepsy is a chronic neurological condition that affects $1 \%$ of people worldwide and is characterized by unprovoked, recurrent seizures. And there is a link between epilepsy and brain damage. Apoptosis and glutamate neurotoxicity have been suggested to be involved in seizure-induced brain damage. It has been determined that apoptosis is involved in the death of neurons after status epilepticus [1] and after prolonged seizures in animal models [2-4]. Beside the modulation of caspases and Bcl-2 molecular pathways of apoptosis are now recognized in human temporal lobe epilepsy (TLE) [5]. On the other hand, in chronic epilepsy models in rodents, there is a consistent marked increase in glutamate release during seizures [6]. In evoked seizures during surgery [7] and spontaneous seizures in ambulatory patients, there is a marked, bilateral transient ictal increase in extracellular hippocampal glutamate levels $[8,9]$. It has been proved that, in epilepsy, glutamate is toxic to neurons [10] and it plays a major role in the initiation and spread of seizure activity in which the excitatory glutamatergic system plays an important role [11]. Pigment epithelium-derived factor (PEDF), a $50-\mathrm{kDa}$ glycoprotein, was first purified from the conditioned medium of cultured primary human fetal retinal pigment epithelial cells in the late 1980s [12].

PEDF belongs to the noninhibitor serpin family group [13]. It is widely expressed in human tissues, including the adult brain, spinal cord, eye, heart [14-16]. As a multifunctional protein, it 
has neurotrophic, neuroprotective and antiangiogenic properties $[17,18]$. In the central nervous system, PEDF is a potential neuroprotective and neurotrophic factor as evidenced by its ability to protect against neuronal apoptosis and to protect neurons against glutamate neurotoxic effects during the immature period and during late postnatal life. It was found that PEDF have neurotrophic effects on primary cultures of rat striata mesencephalic (dopaminergic) neurons [19]. In addition to striatal mesencephalic (dopaminergic) neurons, PEDF exhibits neurotrophic and neuroprotective activities in primary cultures of mature and immature cerebellar granule neurons, protecting them from glutamate-mediated degeneration and from naturally occurring apoptosis [20,21]. It also protects mature and embryonic motor neurons from apoptotic and chronic glutamate-mediated degeneration [14,22]. Moreover, PEDF can protect developing primary hippocampal neurons against glutamate neurotoxicity [23]. It has been reported that PEDF concentration is significantly elevated in the cerebrospinal fluid (CSF) of amyotrophic lateral sclerosis (ALS) patients and this may be an autoprotective reaction [15]. We found an altered PEDF level in the CSF of patients with temporal lobe epilepsy (TLE) when compared with health controls [24]. Considering the known potency of PEDF as a neuron protectant, we designed this study to quantitatively examine whether concentrations of PEDF are decreased or increased in the CSF of drug-effective epilepsy patients compared with drug-refractory epilepsy patients and with healthy controls. Meanwhile, the serum concentrations of PEDF were detected.

\section{Material and Methods}

\section{Subjects}

A total of 52 patients ( 28 male and 24 female) aged 11 to 60 years old (mean \pm S.D., $29.73 \pm 12.87$ years), were recruited from the Epilepsy Clinic, Department of Neurology of the First Affiliated Hospital of Chongqing Medical University. All patients had a comprehensive clinical examination (including a medical history, neurological and psychiatric examination and electroencephalogram). Cranial magnetic resonance imaging and/ or computed tomography scans found no progressive lesions in the central nervous system. All patients were diagnosed as having idiopathic epilepsy and classified according to the criteria proposed by the International League against Epilepsy in 2001 [25]. According to therapeutic efficacy, these patients were divided into two groups: drug-effective $(n=29)$ and drug-refractory $(n=23)$ epilepsy groups. The control group consisted of 20 healthy subjects (11 male and 9 female) aged 14 to 56 years old (mean \pm S.D., $36.15 \pm 15.82$ years) without evidence of neurological or psychiatric disorders or any past history of seizures or exposure to anti-epileptic drugs (AEDs). The ethics committee of the First Affiliated Hospital of Chongqing Medical University approved the study. Informed consent was obtained from all subjects.

\section{Sample Collection and Storage}

For each subject, $2 \mathrm{ml}$ of CSF and $5 \mathrm{ml}$ of venous blood samples were collected. The biochemical profile and total protein of the CSF and serum samples were analyzed by the laboratory department of our hospital. The remaining parts of the CSF samples were centrifuged at $2000 \mathrm{~g}$ for 10 minutes at $4^{\circ} \mathrm{C}$ and stored at $-80^{\circ} \mathrm{C}$ for further analysis. The blood samples were centrifuged at $3000 \mathrm{~g}$ for 15 minutes to obtain the serum, which was then aliquoted and stored at $-80^{\circ} \mathrm{C}$ for further analysis.

\section{PEDF Measurement}

The concentrations of CSF PEDF and serum PEDF were determined using a sandwich enzyme-linked immunosorbent assay with rat antihuman PEDF ELISA Kit (USCN Life Science \& Technology Company, Wuhan, China). Operation steps were performed following the manufacturer's protocol. Dilution of the serum and CSF were 1:10 and 1:5, respectively. Optical densities were determined using a Multiskan Spectrum Microplate Spectraphotometer microplate reader set to $450 \mathrm{~nm}$ (Thermo Fisher Scientific, USA).

\section{Statistical Analysis}

Statistical analysis was performed by SPSS statistics software, version 11.5. Descriptive data were computed using means \pm standard deviation. Differences among drug-effective and drug-refractory epilepsy groups and control group were assessed by a one-way analysis of variance (ANOVA) and a Dunnett t-test. The independent sample t-test was used to compare differences between every two groups. Statistical significance was defined as $\mathrm{p}<0.05$.

\section{Results}

\section{Demographic Characteristics of the Subjects}

(Table 1) shows the clinical data of each subject (Table 2) summarizes the demographic characteristics of the subjects who participated in the study. We observed no significant differences in sex and age among drug-effective, drug-refractory and control groups. However, the duration of the seizure disorder in the drug-refractory group was significantly longer than that in drug-effective group. 
Table 1: Clinical material of the patients in the study.

\begin{tabular}{|c|c|c|c|c|c|c|}
\hline Patients no & Age (year) & Gender & Age at Onset (year) & $\begin{array}{c}\text { Illness Duration of Seizures } \\
\text { (year) }\end{array}$ & AEDs prescribed & Etiological Factor \\
\hline \multicolumn{7}{|c|}{ Drug-Effective Epilepsy Group } \\
\hline 1 & 13 & M & 10 & 3 & VPA & unknown \\
\hline 2 & 13 & $\mathrm{~F}$ & 12 & 1 & PB & unknown \\
\hline 3 & 56 & M & 55 & 1.5 & CBZ & unknown \\
\hline 4 & 54 & M & 53 & 1.25 & CBZ & unknown \\
\hline 5 & 33 & M & 29 & 4 & VPA & unknown \\
\hline 6 & 43 & M & 42 & 1 & TPM & unknown \\
\hline 7 & 17 & M & 16 & 1.33 & LEV & unknown \\
\hline 8 & 60 & M & 58 & 2 & VPA & unknown \\
\hline 9 & 48 & $\mathrm{~F}$ & 45 & 2.83 & TPM & unknown \\
\hline 10 & 24 & $\mathrm{~F}$ & 23 & 1.25 & VPA & unknown \\
\hline 11 & 23 & $\mathrm{~F}$ & 19 & 4.17 & VPA,CBZ & unknown \\
\hline 12 & 30 & $\mathrm{~F}$ & 29 & 1 & LTG & unknown \\
\hline 13 & 45 & M & 43 & 1.67 & VPA & unknown \\
\hline 14 & 17 & M & 15 & 2.08 & VPA & unknown \\
\hline 15 & 24 & $\mathrm{~F}$ & 21 & 3 & TPM & unknown \\
\hline 16 & 23 & $\mathrm{~F}$ & 21 & 1.83 & TPM & unknown \\
\hline 17 & 31 & $\mathrm{~F}$ & 28 & 3 & VPA & unknown \\
\hline 18 & 42 & M & 40 & 2 & LEV & unknown \\
\hline 19 & 18 & $\mathrm{~F}$ & 16 & 2 & VPA & unknown \\
\hline 20 & 23 & $\mathrm{~F}$ & 20 & 2.67 & VPA & unknown \\
\hline 21 & 23 & $\mathrm{~F}$ & 20 & 3 & TPM & unknown \\
\hline 22 & 28 & $\mathrm{~F}$ & 26 & 2.25 & VPA & unknown \\
\hline 23 & 42 & M & 40 & 2 & $\mathrm{CBZ}$ & unknown \\
\hline 24 & 22 & $\mathrm{~F}$ & 20 & 1.75 & TPM & unknown \\
\hline 25 & 46 & M & 45 & 1 & $\mathrm{CBZ}$ & unknown \\
\hline 26 & 20 & M & 18 & 2 & VPA & unknown \\
\hline 27 & 35 & M & 32 & 2.58 & VPA & unknown \\
\hline 28 & 37 & $\mathrm{~F}$ & 35 & 1.92 & $\mathrm{CBZ}$ & unknown \\
\hline 29 & 16 & M & 14 & 2 & VPA & unknown \\
\hline \multicolumn{7}{|c|}{ Drug-Refractory Epilepsy Group } \\
\hline 30 & 41 & M & 1 & 40 & CBZ,PB,VPA,TPM & unknown \\
\hline 31 & 11 & M & 2 & 9 & VPA,TPM,LTG & unknown \\
\hline 32 & 38 & M & 30 & 8 & CBZ, VPA,TPM & unknown \\
\hline 33 & 39 & M & 9 & 30 & CBZ, VPA,TPM & unknown \\
\hline 34 & 24 & $\mathrm{~F}$ & 14 & 10 & CBZ,VPA,TPM,LTG & Unknown \\
\hline 35 & 22 & $\mathrm{~F}$ & 8 & 14 & CBZ,VPA,TPM,LEV & unknown \\
\hline 36 & 28 & M & 8 & 20 & VPA,TPM,LEV & unknown \\
\hline 37 & 13 & $\mathrm{~F}$ & 9 & 4.25 & CBZ, VPA,TPM & unknown \\
\hline 38 & 41 & M & 17 & 24 & VPA,TPM,LEV & unknown \\
\hline 39 & 13 & $\mathrm{~F}$ & 4 & 9 & VPA,TPM,LTG & unknown \\
\hline 40 & 33 & M & 25 & 8 & CBZ ,PB,VPA,TPM & Unknown \\
\hline 41 & 51 & $\mathrm{~F}$ & 30 & 21 & CBZ,VPA,TPM & unknown \\
\hline 42 & 11 & M & 2 & 9 & CBZ,VPA,TPM,LEV & unknown \\
\hline 43 & 38 & M & 20 & 18 & CBZ,VPA,TPM & unknown \\
\hline
\end{tabular}




\begin{tabular}{|c|c|c|c|c|c|c|}
\hline 44 & 26 & $\mathrm{~F}$ & 1 & 25 & CBZ, VPA,TPM,PB & unknown \\
\hline 45 & 37 & $\mathrm{~F}$ & 7 & 30 & VPA,TPM,PB,LEV & unknown \\
\hline 46 & 17 & M & 9 & 8 & CBZ,VPA,TPM,PB & unknown \\
\hline 47 & 20 & M & 2 & 18 & VPA,TPM,PB,LEV & unknown \\
\hline 48 & 32 & $\mathrm{~F}$ & 28 & 4 & CBZ,VPA,TPM,PB & unknown \\
\hline 49 & 45 & M & 39 & 5.5 & CBZ,VPA,TPM,РB & unknown \\
\hline 50 & 28 & M & 12 & 16 & VPA, LTG,TPM,LEV & unknown \\
\hline 51 & 15 & $\mathrm{~F}$ & 0 & 15 & CBZ,VPA,TPM,LEV & unknown \\
\hline 52 & 17 & $\mathrm{~F}$ & 2 & 15 & CBZ,VPA,TPM,PB & unknown \\
\hline \multicolumn{7}{|c|}{ Control Group } \\
\hline 53 & 36 & $\mathrm{M}$ & 0 & 0 & none & none \\
\hline 54 & 14 & $\mathrm{~F}$ & 0 & 0 & none & none \\
\hline 55 & 52 & M & 0 & 0 & none & none \\
\hline 56 & 56 & M & 0 & 0 & none & none \\
\hline 57 & 49 & M & 0 & 0 & none & none \\
\hline 58 & 45 & M & 0 & 0 & none & none \\
\hline 59 & 18 & $\mathrm{~F}$ & 0 & 0 & none & none \\
\hline 60 & 56 & $\mathrm{M}$ & 0 & 0 & none & none \\
\hline 61 & 24 & $\mathrm{~F}$ & 0 & 0 & none & none \\
\hline 62 & 55 & $\mathrm{~F}$ & 0 & 0 & none & none \\
\hline 63 & 30 & $\mathrm{M}$ & 0 & 0 & none & none \\
\hline 64 & 40 & $\mathrm{~F}$ & 0 & 0 & none & none \\
\hline 65 & 20 & $\mathrm{M}$ & 0 & 0 & none & none \\
\hline 66 & 14 & $\mathrm{~F}$ & 0 & 0 & none & none \\
\hline 67 & 36 & $\mathrm{~F}$ & 0 & 0 & none & none \\
\hline 68 & 56 & $\mathrm{M}$ & 0 & 0 & none & none \\
\hline 69 & 35 & $\mathrm{~F}$ & 0 & 0 & none & none \\
\hline 70 & 52 & M & 0 & 0 & none & none \\
\hline 71 & 18 & $\mathrm{~F}$ & 0 & 0 & none & none \\
\hline 72 & 17 & $\mathrm{M}$ & 0 & 0 & none & none \\
\hline
\end{tabular}

Table 2: Clinical characteristics of the subjects.

\begin{tabular}{|c|c|c|c|c|}
\hline & Drug Effective EP (n=29) & $\begin{array}{c}\text { Drug Refractory EP } \\
(\mathbf{n = 2 3 )}\end{array}$ & Control (n=20) & P value \\
\hline Age (yr) & $31.24 \pm 13.56$ & $27.83 \pm 11.98$ & $36.15 \pm 15.82$ & $>0.05$ \\
\hline Gender & & & & \\
\hline Female & 14 & 10 & 9 & $>0.05$ \\
\hline Male & 15 & 13 & 11 & \\
\hline Illness Duration of Seizures & $2.11 \pm 0.84$ (year) & $15.68 \pm 9.37$ (year) & NA & $<0.05$ \\
\hline
\end{tabular}

\section{The concentration of PEDF in CSF and Serum}

(Table 3) summarizes the concentrations of PEDF and total protein in CSF and serum in each group. ANOVA showed that the mean concentrations of CSF-PEDF and serum-PEDF in drugeffective epilepsy, drug-refractory epilepsy and control groups were significantly different among groups, whereas total CSF and serum protein levels were not significantly different among groups. A Dunnett t-test showed that the CSF-PEDF in drug-effective patients was significantly higher than that in the control group, whereas the CSF-PEDF in drug-refractory patients was significantly lower than that in control subjects (Table 4). CSF-PEDF in drugeffective epilepsy patients was significantly higher than that in drug-refractory epilepsy patients. Serum- PEDF concentrations were significantly higher in drug-effective epilepsy patients than controls and drug-refractory patients, while the serum-PEDF has no significant difference between drug-refractory patients and controls (Figure 1). 
Table 3: The concentration of PEDF and total protein in CSF and serum in each group.

\begin{tabular}{|c|c|c|c|c|}
\hline & Drug Effective EP (n=29) & $\begin{array}{c}\text { Drug Refractory EP } \\
(\mathbf{n = 2 3 )}\end{array}$ & Control (n=20) & P value \\
\hline CSF-PEDF $(\mathrm{pg} / \mathrm{ml})$ & $181.90 \pm 55.44$ & $56.83 \pm 11.93$ & $111.15 \pm 9.32$ & $<0.05$ \\
\hline Serum- PEDF (pg/ml) & $156.55 \pm 145.23$ & $14.55 \pm 11.55$ & $62.00 \pm 63.82$ & $<0.05$ \\
\hline CSF-total protein (g/l) & $0.41 \pm 0.15$ & $0.45 \pm 0.23$ & $0.47 \pm 0.09$ & $>0.05$ \\
\hline Serum- total protein (g/l) & $61.66 \pm 4.22$ & $62.35 \pm 3.46$ & $61.30 \pm 3.80$ & $>0.05$ \\
\hline
\end{tabular}

Table 4: Dunnett t-test for drug-effective and drug-refractory EP groups compared with control group.

\begin{tabular}{|c|c|c|}
\hline \multicolumn{2}{|c|}{ CSF-PEDF $(\mathrm{pg} / \mathrm{ml})$} & Drug-refractory EP $(\mathrm{n}=23)$ \\
\hline CSF-PEDF $(\mathrm{pg} / \mathrm{ml})$ & Drug-effective EP $(\mathrm{n}=29)$ & $\mathrm{P}<0.05$ \\
\hline Control $(\mathrm{n}=20)$ & $\mathrm{P}<0.05$ & Drug-refractory EP $(\mathrm{n}=23)$ \\
\hline Serum-PEDF $(\mathrm{pg} / \mathrm{ml})$ & Drug-effective EP $(\mathrm{n}=29)$ & $\mathrm{P}>0.05$ \\
\hline Control $(\mathrm{n}=20)$ & $\mathrm{P}<0.05$ & \\
\hline
\end{tabular}

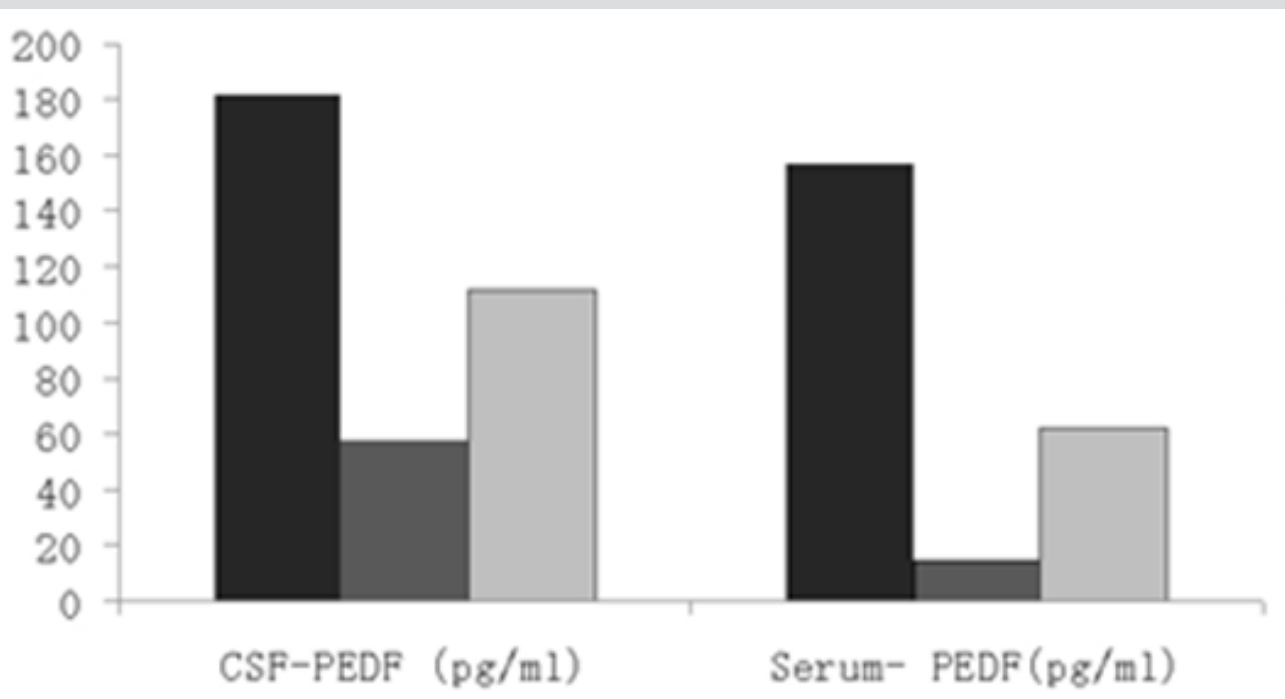

Figure 1: The concentration of PED in CSF nad serum in each group.

\section{Discussion}

Our purpose in this study was to determine whether CSF-PEDF and serum-PEDF are altered in epilepsy patients. Using a sandwich enzyme-linked immunosorbent assay (ELISA), we examined CSFPEDF and serum-PEDF in the drug-effective and drug-refractory epilepsy patients and control subjects. For the first time, we observed that the CSF-PEDF and serum-PEDF in the drug-effective epilepsy patients were significantly higher than those in control and drug-refractory patients. The CSF-PEDF in drug-refractory patients was lower than that in controls. It has been established that PEDF play neuroprotective and neurotrophic role in the central nervous system, not only during the immature period, but also in late postnatal life [15], as evidenced by its ability to protect against neuronal apoptosis and to protect neurons against glutamate neurotoxic effects or neurodegeneration [14, 20-23]. PEDF has been detected in CSF Kuncl et al. $[14,15,26]$ found that CSF-PEDF were significantly elevated in ALS patients when compared with other severe denervating diseases or other neurodegenerative diseases and proposed that the surprisingly high CSF-PEDF may be an autoprotective reaction Yamagishi et al. [26,15] further suggested that CSF-PEDF may reflect cerebral PEDF turnover and provide a means for monitoring neuronal perturbation in the early stage of Alzheimer's disease (AD) [26]. In the current study, PEDF was detected in the CSF of all subjects, as is consistent with previous studies. We found that the CSF-PEDF in drug-effective epilepsy patients was significantly higher than that in controls and drugrefractory patients, and the CSF-PEDF in drug-refractory patients was significantly lower than that in controls. In addition, the illness duration of drug-effective epilepsy patients was significantly shorter than that of the drug-refractory epilepsy patients, which accordingly indicates early and advanced stages of the disease. Considering the potential neurotrophic and neuroprotective properties of PEDF, we propose that increased CSF-PEDF in drugeffective epilepsy patients may reflect the increased neurotrophic/ 
neuroprotective activities of PEDF in the early stage of disease, whereas decreased CSF-PEDF in drug-refractory epilepsy patients may reflect decreased neurotrophic/neuroprotective activities of PEDF. The results also reflect the cerebral turnover of PEDF in these two groups of patients.

Like CSF-PEDF, the serum-PEDF in the drug-effective epilepsy patients was significantly higher than those in control and drugrefractory patients. The serum-PEDF in drug-refractory patients was lower than that in controls, although there was no significant difference. A possible explanation is that serum PEDF may pass the blood brain barrier (BBB) after a seizure. Increasing evidence has indicated that the BBB plays an important role in epilepsy, and BBB leakage has been observed in human and experimental epilepsy $[27,28]$. The PEDF in serum might be transported through the BBB and reach the CSF, where it exhibits its neurotrophic/ neuroprotective activities. We suggest that the serum PEDF may reflect CSF PEDF.

\section{Conclusion}

In conclusion, this study showed that compared with normal controls, the CSF-PEDF and serum-PEDF were increased in drugeffective epilepsy patients and the CSF-PEDF decreased in drugrefractory epilepsy patients. We suggest that the neurotrophic/ neuroprotective activities of PEDF are increased in drug-effective epilepsy patients, while these activities are decreased in drugrefractory epilepsy patients. At present, the mechanisms of altered CSF-PEDF and serum-PEDF concentrations in epilepsy patients are unknown. Further study is necessary to explore whether PEDF may be a useful neuroprotective therapeutic factor or a biomarker in the differentiation of drug-effective epilepsy from drug-refractory epilepsy.

\section{Acknowledgement}

This work was supported by grants from the National Natural Science Foundation of China (81201002).

\section{References}

1. Liou AK, Clark RS, Henshall DC, Yin XM, Chen J (2003) To die or not to die for neurons in ischemia, traumatic brain injury and epilepsy: a review on the stress-activated signaling pathways and apoptotic pathways. Prog Neurobiol 69(2): 103-142.

2. Filipkowski RK, Hetman M, Kaminska B, Kaczmarek L (1994) DNA fragmentation in rat brain after intraperitoneal administration of kainate. Neuroreport 5(12): 1538-1540.

3. Pollard H, Charriaut Marlangue C, Cantagrel S, Represa A, Robain O, et al (1994) Kainate-induced apoptotic cell death in hippocampal neurons. Neuroscience 63(1): 7-18.

4. Shinoda S, Araki T, Lan JQ, Schindler CK, Simon RP, et al. (2004) Development of a model of seizure-induced hippocampal injury with features of programmed cell death in the BALB/c mouse. J Neurosci Res 76(1): 121-128.

5. Henshall D C, Simon RP (2005) Epilepsy and apoptosis pathways. J Cereb Blood Flow Metab 25(12): 1557-1572.

6. Chapman AG (1998) Glutamate receptors in epilepsy. Prog Brain Res 116: 371-383.
7. Ronne Engstrom E, Hillered L, Flink R, Spannare B, Ungerstedt U, et al (1992) Intracerebral microdialysis of extracellular amino acids in the human epileptic focus. J Cereb Blood Flow Metab 12(5): 873-876.

8. During MJ, Spencer DD (1993) Extracellular hippocampal glutamate and spontaneous seizure in the conscious human brain. Lancet 341(8861): 1607-1610

9. Wilson CL, Maidment NT, Shomer MH, Behnke E J, Ackerson L, et al. (1996) Comparison of seizure related amino acid release in human epileptic hippocampus versus a chronic, kainate rat model of hippocampal epilepsy. Epilepsy Res 26(1): 245-254.

10. Savaskan NE, Brauer AU, Kuhbacher M, Eyupoglu IY, Kyriakopoulos A et al. (2003) Selenium deficiency increases susceptibility to glutamateinduced excitotoxicity. FASEB J 17(1): 112-114.

11. Chapman AG (2000) Glutamate and epilepsy. J Nutr 130(4):1043-1045.

12. Tombran Tink J, Johnson LV (1989) Neuronal differentiation of retinoblastoma cells induced by medium conditioned by human RPE cells. Invest Ophthalmol Vis Sci 30(8): 1700-1707.

13. Becerra SP, Sagasti A, Spinella P, Notario V (1995) Pigment epitheliumderived factor behaves like a noninhibitory serpin. Neurotrophic activity does not require the serpin reactive loop. J Biol Chem 270(43): 25992 25999.

14. Bilak MM, Corse AM, Bilak SR, Lehar M, Tombran Tink J, et al. (1999) Pigment epithelium-derived factor (PEDF) protects motor neurons from chronic glutamate-mediated neurodegeneration. J Neuropathol Exp Neurol 58(7): 719-728.

15. Kuncl RW, Bilak MM, Bilak SR, Corse AM, Royal W, et al. (2002) Pigment epithelium-derived factor is elevated in CSF of patients with amyotrophic lateral sclerosis. J Neurochem 81(1): 178-184.

16. Tombran Tink J, Mazuruk K, Rodriguez IR, Chung D, Linker T, et al. (1996) Organization, evolutionary conservation, expression and unusual Alu density of the human gene for pigment epithelium-derived factor, a unique neurotrophic serpin. Mol Vis 2: 11.

17. Dawson DW, Volpert OV, Gillis P, Crawford SE, Xu H, et al. (1999) Pigment epithelium-derived factor: a potent inhibitor of angiogenesis. Science 285(5425): 245-248.

18. Taniwaki T, Becerra SP, GJ Chader SP, Schwartz JP (1995) Pigment epithelium-derived factor is a survival factor for cerebellar granule cells in culture. J Neurochem 64(6): 2509-2517.

19. Falk T, Zhang S, Sherman S J (2009) Pigment epithelium derived factor (PEDF) is neuroprotective in two in vitro models of Parkinson's disease. Neurosci Lett 458(2): 49-52.

20. Araki T, Taniwaki T, Becerra SP, Chader GJ, Schwartz JP (1998) Pigment epithelium-derived factor (PEDF) differentially protects immature but not mature cerebellar granule cells against apoptotic cell death. J Neurosci Res 53(1): 7-15.

21. Taniwaki T, Hirashima N, Becerra SP, Chader GJ, Etcheberrigaray R, et al (1997) Pigment epithelium-derived factor protects cultured cerebellar granule cells against glutamate-induced neurotoxicity. J Neurochem 68(1): 26-32.

22. Houenou LJ, D Costa AP, Li L, Turgeon VL, Enyadike C, et al. (1999) Pigment epithelium-derived factor promotes the survival and differentiation of developing spinal motor neurons. J Comp Neurol 412(3): 506-514.

23. De Coster MA, Schabelman E, Tombran Tink J, Bazan NG (1999) Neuroprotection by pigment epithelial-derived factor against glutamate toxicity in developing primary hippocampal neurons. J Neurosci Res 56(6): 604-610.

24. Xiao F, Chen D, Lu Y, Xiao Z, Guan LF, et al. (2009) Proteomic analysis of cerebrospinal fluid from patients with idiopathic temporal lobe epilepsy. Brain Res 1255: 180-189.

25. Seino M (2006) Classification criteria of epileptic seizures and syndromes. Epilepsy Res 70(1): 27-33. 
26. Yamagishi S, Inagaki Y, Takeuchi M, Sasaki N (2004) Is pigment epithelium-derived factor level in cerebrospinal fluid a promising biomarker for early diagnosis of Alzheimer's disease? Med Hypotheses 63(1): 115-117.

27. Oby E, Janigro D (2006) The blood-brain barrier and epilepsy. Epilepsia 47(11): 1761-1774.

\section{ISSN: 2574-1241}

DOI: 10.26717/BJSTR.2019.18.003184

Qiao Cheng. Biomed J Sci \& Tech Res

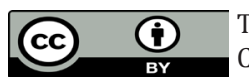

This work is licensed under Creative Commons Attribution 4.0 License

Submission Link: https://biomedres.us/submit-manuscript.php
28. Rigau V, Morin M, Rousset MC, De Bock F, Lebrun A, et al. (2007) Angiogenesis is associated with blood-brain barrier permeability in temporal lobe epilepsy. Brain 130(7): 1942-1956.

Assets of Publishing with us
$\begin{aligned} & \text { BIOMEDICAL } \\ & \text { RESEARCHES }\end{aligned}$
- Global archiving of articles

